whole inquiry, and which I have overlooked in Mr. Darwin's books if it is to be found there, is a discussion of the causes which produce sterility and those which favour fertility in races. He no doubt discusses with ingenuity the problem of the sterility of mules and of crosses between different races, but I have nowhere met with the deeper and more inuprrtant discussion of the general causes that induce or check the increase of races. The facts upon which I rely are very common-place, and are furnished by the smallest plot of garden or the narrowest experience in breed. ing domestic animals. The gardener who wants his plants to blossom and fruit takes care that they shall avoid a vigorous growth. He knows that this will inevitably make them sterile; that either his trees will only bear distorted flowers, that they will have no seed, or bear no blossoms at all. In order to induce flowers and fruit, the gardener checks the growth and vigour of the plant by pruning its roots or its branches, depriving it of food, \&c., and if he have a stubborn pear or peach tree which has long refused to bear fruit, he adopts the hazardous, but often most successful, plan of ringing its bark. The large fieshy melons or oranges have few seeds in them. The shrivelled starvelings that grow on decaying branches are full of seed. And the rule is universally reccgnised among gardeners as applying to all kinds of cultivated plants, that to make them fruitful it is necessary to check their growth and to weaken them. The law is no less general among plants in a state of nature, where the individuals growing in rich soil, and which are well-conditioned and growing vigorously, have no flowers, while the starved and dying on the sandy sterile soil are scattering seed everywhere.

On turning to the animal kingdom, we find the law no less true. "Fat hens won't lay," is an old fragment of philosophy. The breeder of sheep and pigs and cattle knows very well that if his ewes and sows and cows are not kept lean they will not breed; and as a startling example I am told that to induce Alderney cows, which are bad breeders, to be fertile they are actually bled, and so reduced in condition. Mr. Doubleday who wrote an admirable work in answer to Malthus, to which I am very much indebted, has adduced overwhelming evidence to show that what is commonly known to be true of plants and animals is especially true of man. He has shown how individuals are affected by generous diet and good living, and also how classes are so affected. For the first time, so far as I know, he showed why population is thin and the increase small in countries where flesh and strong food is the ordinary diet, and large and increasing rapidly where fish or vegetable or other weak food is in use; that everywhere the rich, luxurious, and well fed classes are rather diminishing in numbers or stationary; while the poor, under-fed, and hard-worked are very fertile. The facts are excceedingly numerous in support of this view, and shall be quoted in your pages if the result is disputed. This was the cause of the decay of the luxurious power of Rome, and of the cities of Mesopotamia. These powers succumbed not to the exceptional vigour of the barbarians, but to the fact that their populations had diminished, and were rapidly being extinguished from internal causes, of which the chief was the growing sterility of their inhabitants.

The same cause operated to extinguish the Tasmanians and other savage tribes which have decayed and died out, when brought into contact with the luxuries of civilisation, notwithstanding every effort having been made to preserve them. In a few cases only have the weak tribes been supplanted by the strong, or weaker individuals by stronger; the decay has been internal, and of remoter origin. It has been luxury and not want; too much vigour and not too little, that has eviscerated and destroyed the race. If this law then be universal both in the vegetable and animal kingdoms, a law too, which does not operate on individuals and in isolated cases only, but universally, it is surely incumbent upon the supporters of the doctrine of Natural Selection, as propounded by Mr. Darwin, to meet and to explain it, for it seems to me to cut very cleeply into the foundations of their system. If it be true that, far from the strong sur viving the weak, the tendency among the strong, the well fed, and highly favoured, is to decay, become sterile, and die out, while the weak, the under-fed, and the sickly are increasing at a proportionate rate, and that the fight is going on everywhere among the individuals of every race, it seems to me that the theory of Natural Selection, that is, of the persistence of the stronger, is false, as a general law, and true only of very limited and exceptional cases. This paper deals with one difficulty only, others may follow if this is acceptable.

Derby liouse, Eccles

\section{Ocean Currents}

Mr. Proctor concludes his letter on Ocean Currents, in NATURE for June 15, with the remark that in theories respecting oceanic circulation "the vast distance separating the Polar from the Equatorial regions must not be overlooked." Will you allow me to point out to him that in the experiment he suggests, that vast distance is entirely overlooked; that, in fact, any such experiment, with whatever difference of detail it may be performed, whether in his cylinder or in Dr. Carpenter's trough, in no way illustrates the natural condition of things, and in no way tends to answer that objection to the "temperature" theory of currents which is founded on the infinitesimal nature of the thermometric gradients. The difference of temperature between Arctic and Equatorial water is about $50^{\circ} \mathrm{F}$., or $1^{\circ} \mathrm{F}$. in 100 miles; or, reducing it to smaller units suitable for an experiment, is $\frac{1}{600000}$ of a degree in one foot; this, if the experimental trough is five feet long, or if the cylinder is ten feet in diameter, gives an extreme difference of $\frac{1}{120000}$ of a degree of Fahrenheit's scale. Can such a difference be represented in any experiment? I think not; but no experiment which shows a much greater relative difference can be accepted as satisfactory for it is the infinitesimal nature of the thermometric gradient existing in the ocean that consticutes the physical objection to the temperature theory. There are other objections which I will not allude to now; but it is manifestly no answer to this one objection to show that under certain other circumstances-which bear no resemblance in degree to those of nature-hot water and cold will establish a circulation. I, for one, have, for a good many years, been perfectly well aware that they will; but I doubt if it has ever been shown that a sensible motion will result from a. thermometric gradient of $\frac{1}{\text { o }} 00 \mathrm{~d}$ of a degree in a foot.

\section{J. K. LAUGHTON}

\section{Alpine Floras}

THE fact mentioned in last week's NATURE of the absence of any Alpine flora on the Atlas Mountains, Morocco, though disappointing, is interesting. It seems to show that, during the glacial period, icebergs did not drift to the Atlas. This, how ever, must have been from local causes only. Mr. Wallace found a European flora on a mountain in the Eastern Archipelago-I think in Borneo-which, most probably, must have got there during the glacial period.

Old Forge, Dunmurry, Co. Antrim, June is

\section{A Suggestion}

Is it possible that the following facts may account for the presence of Elastrus dolosus in the Azores? At all events, I offer them as suggestive, and for the information of Messrs. Wallace, Godman, Murray, Crotch, \&c.

Lawrence Almeida, son of the first Portuguese Viceroy in India, was the first Eurupean known to visit the coast of Madagascar in the year 1506. The Portuguese circumnavigated the whole island within two years, and subsequently constantly anchored at it in their voyages to the East Indits. They also established a settlement on a steep rock on the bank of the river Franchere and near the village of Hatore, in the province of Anosi (i.e., at the south-eatern extremity of the island). The valuable timber, as ebony, as well as the rich dye-woods, would be well worth taking to Europe, and thus doubtless afforded a conveyance for living larval or pupal Elaters, without any rare or improbable concurrence of events, to the Portuguese islands in the Atlantic. Many of the extremely beautiful and attractive flowering shrubs and plants would also not improbably be forwarded to Europe by the same route, in which some Elaterida might find shelter. Is the lapse of 300 years sufficient to account for change of development?

Southsea

S. P. OUIVER

\section{HYDROUS SILICATES INZECTING THE PORAS OF FOSSILS}

R. T. STERRY HUNT directed attention some time ago* to a remarkable limestone of Silurian age from Pole Hill, New Brunswick, in which I had found the

* Proceedings of the Natural History Society of Montreal, 
cavities of fossil crinoids to be filled with a siliceous substance perfectly injecting their most delicate cellular structure, and which Dr. Hunt, on chemical analysis, found to be a hydrous silicate allied to jollyte. I have since, in examining with the microscope various specimens of limestone in the collection of McGill College, met with a British example of this kind of injection, to which I would wish to direct the attention of your microscopists. It is a specimen of olivaceous, imperfectly crystalline limestone, labelled Llangedoc, Wales. The only distinct fossil which it contains is a small body having the characters of the genus Verticillopora. It is filled, however; with crinoidal fragments and fragments of shells, and, when sliced, displays a few very minute univalves, probably of the genus Murchisonia, and also portions of a sponge-like organism with square meshes. The pores and cavities of many of these fossils are filled with a greenish or brownish finely crystalline silicate, which must have been introduced when the organic bodies were still recent, and which Dr. Hunt has ascertained to have the following composition :-

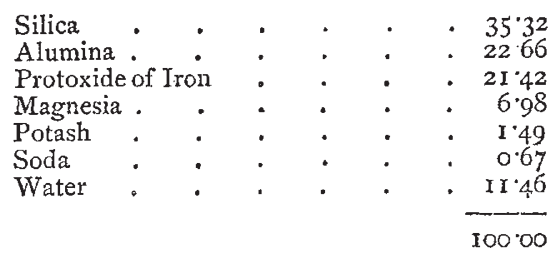

So that this mineral is almost identical with jollyte. The fact that it fills the minute pores and cavities of the fossils can be seen in transparent slices, especially under pola. rised light, and also in decalcified specimens. The filling is not, however, so perfect as in the New Brunswick specimens above alluded to. The best, which I suppose to be Upper Silurian, is worthy of the attention of those who may have access to it, as presenting an interesting example of Silurian fossils preserved in the same way with the Laurentian Eozöon. It affords another palæozoic illustration of a mode of preservation of the structures of fossils, which, though perhaps more prevalent in the Laurentian and Cretaceous than in any intervening periods, is to be met with here and there throughout the geological series, and is of equal interest to the palæontologist and the chemical geologist.

Montreal, June 8

\section{NEW THEORY OF SUN-SPOTS}

A LATE number $(1,835)$ of the Astronomische $N$ achrich ten reproduces from the notices of the Royal Saxon Scientific Society a paper on the above subject by Pro fessor Zöllner. The author believes that he is the first who has attempted to account for the periodicity of the spots by agencies confined to the sun itself, while he rejects the notion of planetary influence to which the phenomenon has been commonly attributed. In this, how. ever, he is not quite correct, for in the April numbers of Cosmos last year there appeared a transcript of a paper read before the Belgian Academy of Sciences, by M. Bernaerts, who tries to explain the various phenomena of the sun.spots without reference to any extra-solar action.

Prof. Zöllner, like M. Bernaerts, accepts the theory of a liquid forming the surface of the sun; but while the Belgian savant considers the spots as perforations in the liquid layer traversed by downpouring currents of gases that had previously risen through the liquid from the gaseous nucleus, Prof. Zöllner believes the spots to be formations of slag or scoriæe caused by a certain local cooling of the liquid surface. Over this glowing liquid is a glowing atmosphere, which contains, in a vaporous state, a portion of the matter belonging to the liquid. The same as on the earth, if this atmosphere is cloudless and calm, radiation and cold are induced; and where this occurs the slag-like products are formed, and spots become visible. But vaporous condensation is also a consequence of the cold. Clouds, therefore, are developed, the radiation is checked, the liquid surface regains its former heat, and the spots are dissolved and disappear; so that the very cause that effects their formation also tends to their dissolution. The repetition of the same operations gives the spots the character of "intermittent phenomena;" but their occurrence, as well as their duration, depends on such a complication of meteorological processes that those phenomena cannot be considered otherwise than as perfectly casual.

The action of a spot on the atmosphere in cooling it, and causing cloudlike condensations that oppose radiation and restore the heat, makes the presence of a great spot unfavourable to the formation of other spots, and Prof. Zöllner arrives at the conclusion that "a sun-spot exerts within a certain area, and according to its size, an influence that prevents or obstructs the formation of other sun-spots." Thus, it appears, he explains the isolation of the spots. But they occur also in groups over a wide extent of surface, and he infers that "the same conditions of the solar atmosphere that induce the formation of a. spot in any one place, prevail in general over a larger space than that occupied by the spot, so that within the area influenced by those favourable conditions, the simultaneous production of other spots is more likely than elsewhere." The size of the spots depends plainly not on the amount of radiation alone, for the slay.like products have cohesive properties like our ice-flates.

I candidly admit that all this is by no means so very plain to me after reading the theory of the isolation of the spots; and I would refer the reader to the original for a better understanding of the two theories relating to the isolation and the grouping, than I have been able to attain to. I would al, 0 refer to the original for the Professor's views of the oscillations of solar temperature and the periodicity of the spots, which he discusses in several paragraphs.

The appearance of the spots in certain zones on both sides of the equator ke explains as the effect of currents in the liquid stratum. He asks us to imagine, in the first place, a motionless, atmosphere-enveloped globe maintained at a constant high temperature; and, after explaining the results, he tells us to fancy such a globe with a liquid envelope heated at bottom by contact with the surface beneath it, and cooled above by radiation. The lower parts of the liquid have a tendency to rise on account of their lower specific gravity, but their ascent anywhere is impossible unless somewhere else a sinking takes place. With equal conditions everywhere prevail:ng, no motion in either direction could occur; but those equal conditions do not exist on the sun, whose axial rotation diminishes the force of gravity at the equator. This therefore favours an ascent of the heated lower portions of the liquid at the equator, and a sinking of the cooler upper parts in the regions of the poles. Two streams are thus induced; one below flowing toward the equator, and one above in a contrary direction. The former as it progresses gains in temperature by contact with the hot surface of the globe; while the latter in its sub-aerial route loses heat by radiation. Thus the polar regions of the sun are made cooler than the equatorial, as has, in fact, been shown by Secchi's investigations.

These movements in the enveloping liquid (fiissigen Umhiullungen) are the cause of atmospheric disturbances, producing in certain places a lowering of temperature and condensation. The fall in temperature is favoured in two ways-by the mixing of the equatorial and polar streams in high latitudes, and by the ascent of an air-current at the equator. As this aircurrent cools in rising its vaporous constituents are partly condensed in the form of clouds. Yet these clouds need not at all be of so low a temperature as to appear to us 